\title{
THE RESISTANCE TO WEAR OF CARBON STEELS
}

\author{
By Samuel J. Rosenberg
}

\section{ABSTRACT}

A study was made of the effect of heat treatment and carbon content upon the wear resistance of carbon steels as determined by the Amsler machine (combined rolling and sliding friction under heavy pressures). Annealed steels gave poor wear-resisting qualities unaffected by carbon content. Normalized steels showed less wear resistance in the low-carbon range than the annealed steels, but in the high-carbon range approached the relatively high wear resistance of the hardened steels. Hardened steels showed a very rapid increase in wear resistance with increased carbon content, this increase becoming relatively small after about 0.6 per cent carbon. Tempering a hardened steel resulted in a gradual lowering of the wear resistance.

The microstructures of the steels adjacent to the worn surfaces showed that this particular type of wear (combined rolling and sliding friction under heavy pressures) was generally accompanied by severe distortion of the structure. A martensitic-troostitic matrix was the most resistant to wear. Steels containing lamellar pearlite showed excellent wear resistance, while steels containing granular pearlite had poor resistance to wear. The presence of free ferrite, or of free cementite as spheroids, is detrimental to the wear resistance.

\section{CONTENTS}

I. Introduction

II. Method of test

III. Results of the tests.

1. Film formation

420

Cests

2. Interpretation of test data

3. Effect of pressure between the test specimens

4. Materials tested.

5. Effect of carbon content on the resistance to wear

6. Effect of tempering temperature on the resistance to wear.- 424

7. Examination of the abraded surfaces... 425

IV. Discussion of results

V. Summary and conclusions. 428

VI. Acknowledgments

\section{INTRODUCTION}

The resistance of carbon steels to abrasion by sand as determined by the Brinell machine has been reported in a previous paper. ${ }^{1}$ As a continuation of this work, the present paper reports a study of the resistance of carbon steels to metal-to-metal wear against a hardened eutectoid carbon steel under combined sliding and rolling friction.

\section{IVETHOD OF TEST}

The apparatus used in this investigation for the evaluation of wear resistance was the Amsler machine. This machine has been described in detail in a previous paper. ${ }^{2}$

The test specimens used were in the form of small cylinders, 2 inches in diameter and 0.4 inch thick. The specimens were all

1 Samuel J. Rosenberg, The Resistance of Steel to A brasion by Sand, B. S. Jour. Research, 5 (RP 214); September, 1930; also Trans. Am. Soc. Steel Treat., 18, p. 1093; 1930.

I H. J. French, S. J. Rosenberg, W. LeC. Harbaugh, and H. C. Cross, Wear and Mechanical Properties of Railroad Bearing Bronzes at Different Temperatures. B. S. Jour. Research, 1 (RP 13); September, 1928. 
finish ground to size. The finished surfaces were produced by wet grinding with a medium hard No. 46 wheel.

* All steels were tested against an arbitrarily selected "standard" steel. This standard was a 0.81 per cent carbon steel normalized at $810^{\circ} \mathrm{C}$. $\left(1,490^{\circ} \mathrm{F}\right.$.), water quenched from $780^{\circ} \mathrm{C}$. $\left(1,435^{\circ} \mathrm{F}\right.$. $)$, and tempered at $260^{\circ} \mathrm{C}$. ( $\left(500^{\circ} \mathrm{F}\right.$.). The Rockwell "C" scale hardness resulting from this treatment was just under 60 . In all tests the standard specimen was mounted on the lower shaft of the machine, which was rotated at about $220 \mathrm{r}$. p. m. The test specimen was mounted on the upper shaft, its speed being about 200 r. p. m. In addition to the slip resulting from this difference in speed, the cam which is available on the Amsler machine for producing lateral motion of the upper specimen was used.

All tests were made in duplicate and a new standard specimen was used for each test specimen. Wear was measured by the losses in weight of both the specimens.

\section{RESULTS OF THE TESTS}

\section{FILM FORMATION}

The formation of surface films on specimens tested in the Amsler machine is a familiar phenomenon. In the case of the wear of steel against steel, this film appears to be an oxide of iron and to act as an abrasive. Fink ${ }^{3}$ has shown that the partial or complete removal of this film causes a decided decrease in the rate of wear. He tested carbon steels in the Amsler machine under atmospheric conditions and found that a considerable amount of wear took place. When the same steels were inclosed in a gas-tight cell filled with nitrogen and tested under the same conditions of speed and pressure as before, no wear took place, the test surfaces being smooth and bright at the end of the test. These films are a natural result of the rolling and sliding abrasion of steel against steel under heavy pressures in the presence of air and the absence of lubrication. No attempt was made to remove films during the tests reported in this paper.

When two specimens of the same steel which have also been given the same heat treatment are tested in the Amsler machine, the upper specimen, which travels at the lower angular velocity, loses more weight than the lower specimen. The appearances of the films produced are quite different; the lower specimen has a much heavier film. The films produced on steels of like composition and treatment are shown in Figure 1. Since it is the lower specimen which forms the heavier film and the upper specimen which suffers the greater loss in weight, it was decided to mount the "standard" specimen on the lower shaft.

A possible explanation for the difference in losses of weight of two specimens treated alike lies in the fact that the lower specimen forms the heavier film. This film, which acts as an abrasive on the upper specimen, exerts a certain protective influence on the lower one.

\section{INTERPRETATION OF TEST DATA}

The weight loss of the upper (test) specimen was plotted against the revolutions of the lower (standard) specimen to show the relation of wear to slip. This may be conveniently expressed as weight lost per 10,000 revolutions, which was the ordinary duration of a test

'M. Fink, Wear Oxidation, a New Component of Wear, Trans. Am. Soc. Steel Treat., 18, p. 204 ;1930. 
B. S. Journal of Research, RP348

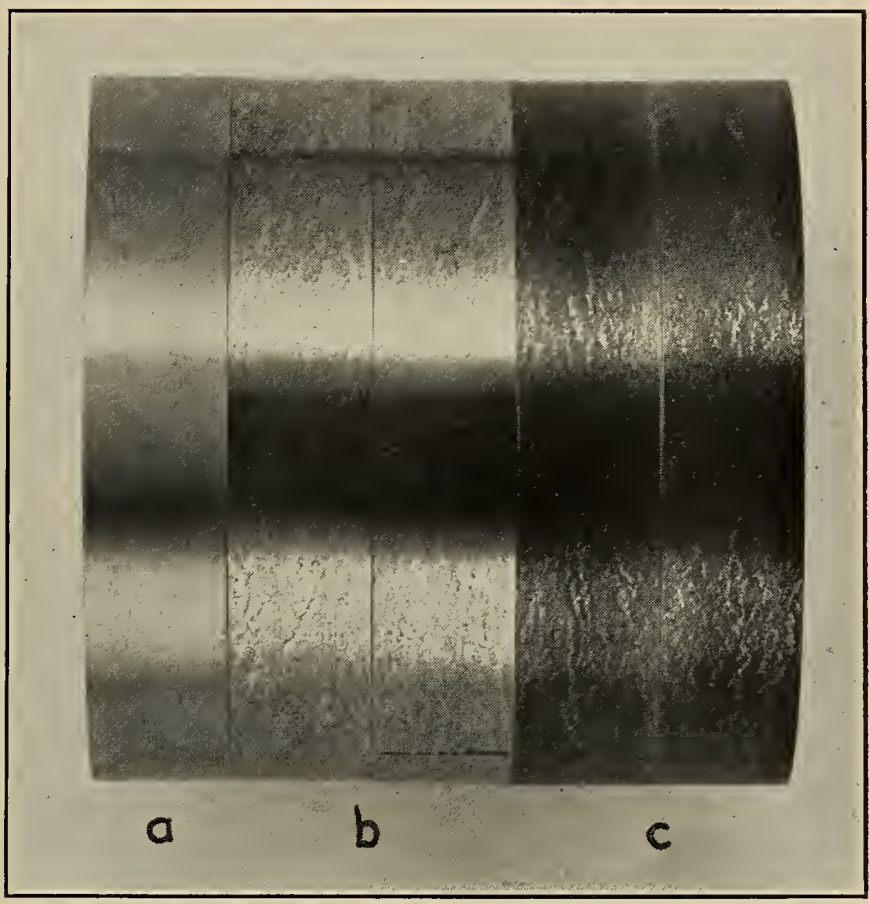

Figure 1.-Appearance of specimens before and after test

All specimens are 0.81 per cent carbon, water-quenched and tempered at $260^{\circ} \mathrm{C}$. $\left(500^{\circ} \mathrm{F}\right.$.). 'Test load was $60 \mathrm{~kg}$. a, Original ground surface; $b$, appearance of upper specimen (light film); $c$, appearance of lower specimen (heavy film). 
period. By plotting the weight loss against the work, as calculated from the integrating device on the Amsler machine, the wear per unit of work may be obtained.

Under similar conditions of test, the evaluation of wear by either method generally gives quite similar results. Results more truly

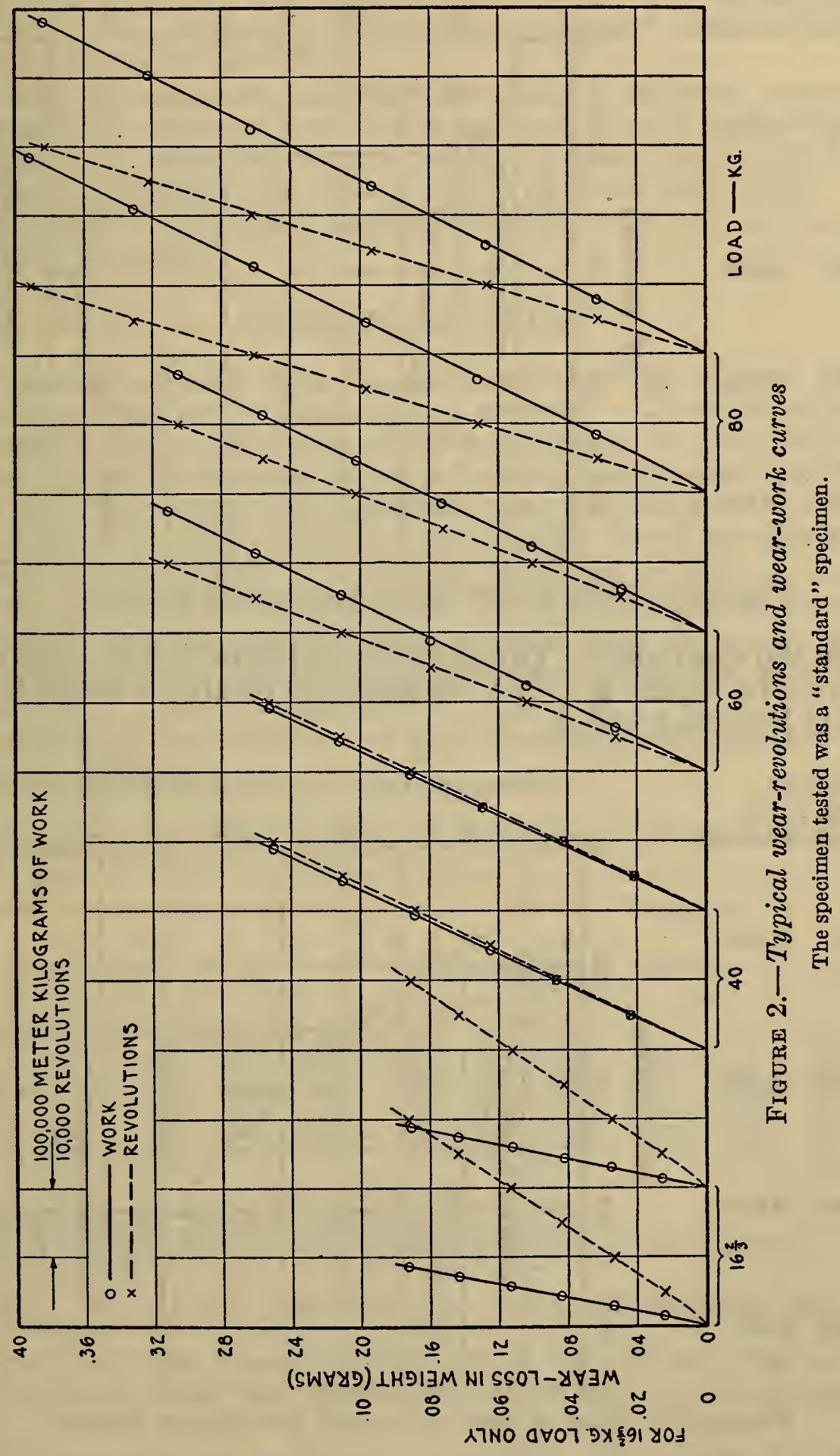

indicative of the materials are obtained, however, when the wear is correlated with the frictional work which caused it. For this reason, all comparisons of materials tested are based upon the wear per unit of work. Figure 2 illustrates wear-revolutions and wear-work curves. 


\section{EFFECT OF PRESSURE BETWEEN THE TEST SPECIMENS}

A series of tests were made with two sets of "standard" specimens tested against each other to determine the effect of increasing pressure

PRESSURE

LBS.PER SQ.IN.

MAXIMUM MINIMUM

$39,000 \quad 31,000$

$60,000 \quad 48,000$

$74,000 \quad 58,000$

85,000

67,000
WEIGHT (IN GRAMS) LOST PER 100,000 M.KG. OF WORK

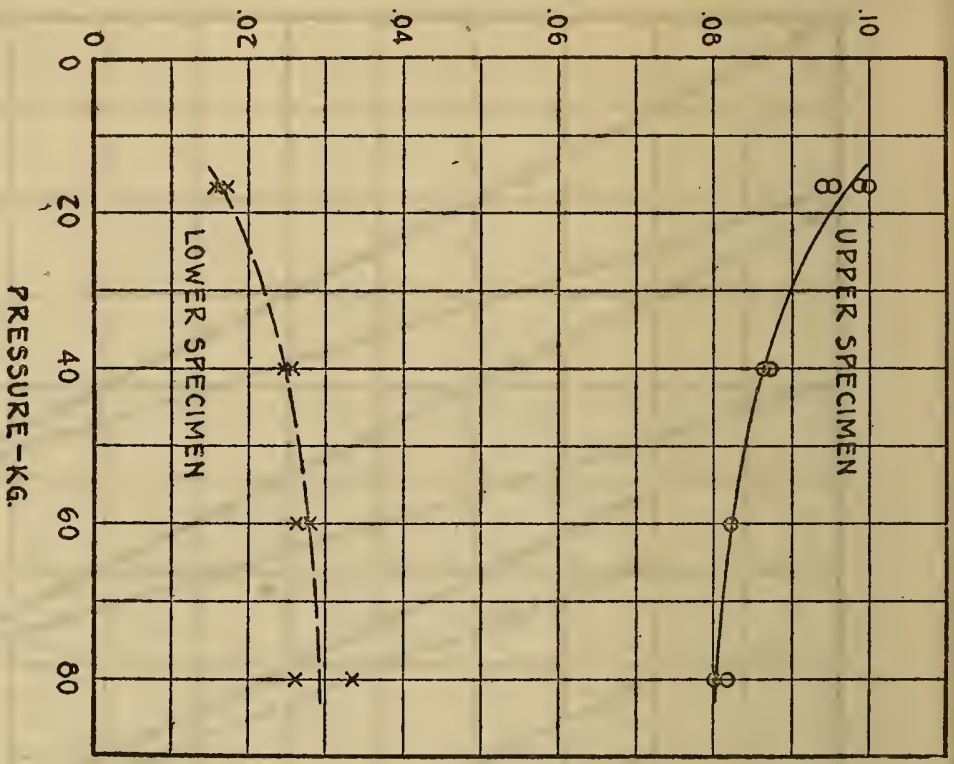

FIGURE 3.-Effect of pressure on wear per unit of work

between the specimens. The experimental data of this series of tests are shown in Figure 2. The comparative results of these tests are shown in Figures 3 and 4.

PRESSURE

LBS. PER SQ.IN.

MAXIMUM MINIMUM

$39,000 \quad 31,000$

$60,000 \quad 48,000$

$74,000 \quad 58,000$

$85,000 \quad 67,000$
WEIGHT (IM GRAMS) LOST PER 50,000 REVOLUTIONS

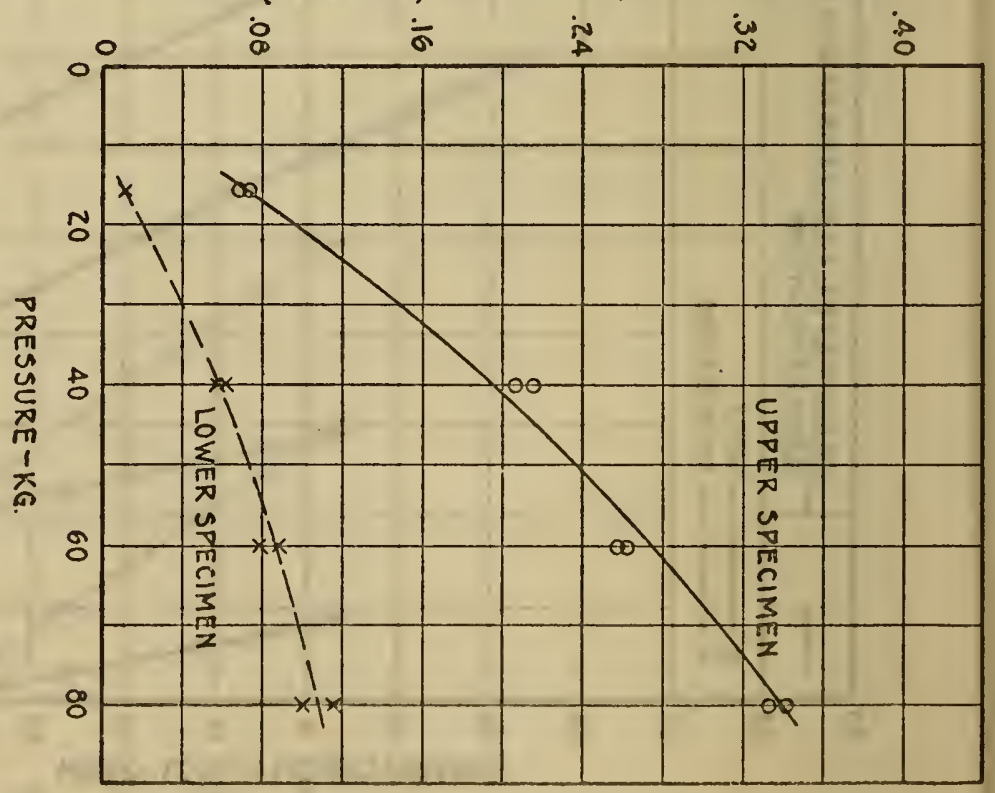

Figure 4.-Effect of pressure on wear per distance traveled

The wear per unit of work of the upper specimen decreased as the pressure increased, this decrease becoming less with increasing pressure. The lower specimen, on the other hand, showed an increased amount of wear per unit of work as the pressure increased. This 
would seem to indicate that, were the pressure sufficiently great, the upper and lower specimens would both lose the same amount of weight. This, however, seems improbable because the curves show evidences of becoming asymptotic. Unfortunately, the frictional torque developed under a total load of $80 \mathrm{~kg}$ was so great that if a higher pressure had been used the counterweights would not have been sufficiently heavy to balance the torque developed, and no measure of the work could have been obtained.

As would be expected, the wear per unit of distance traveled increased with the pressure, both in the upper and lower specimens.

For the tests described in this report, a total load of $60 \mathrm{~kg}$ was chosen as a standard load under which all tests were made. This corresponds to a maximum pressure of $74,000 \mathrm{lbs} . /$ in. $^{2}$ as calculated from Hertz' formulas. ${ }^{4}$

\section{MATERIALS TESTED}

The materials tested were all plain carbon steels, chosen so as to give a range from low to high carbon content. Three series of tests were made namely, of the steels as normalized, as normalized and annealed, and as normalized, water quenched, and tempered at $260^{\circ} \mathrm{C}$. $\left(500^{\circ} \mathrm{F}\right.$.). This tempering treatment was necessary in the case of the higher carbon steels in order to prevent any cracking which might otherwise have occurred. In order to keep the treatments uniform, all of the quenched steels were given the same tempering treatment.

In addition to these tests, a further series of tests was made upon the 0.81 per cent carbon steel to study the effect of tempering temperature between $260^{\circ} \mathrm{C}$. $\left(500^{\circ} \mathrm{F}\right.$. $)$ and $600^{\circ} \mathrm{C}$. $\left(1,100^{\circ} \mathrm{F}\right.$.).

The chemical compositions and heat treatments of the steels tested are given in Table 1.

TABLE 1.-Compositions and heat treatments of the steels tested

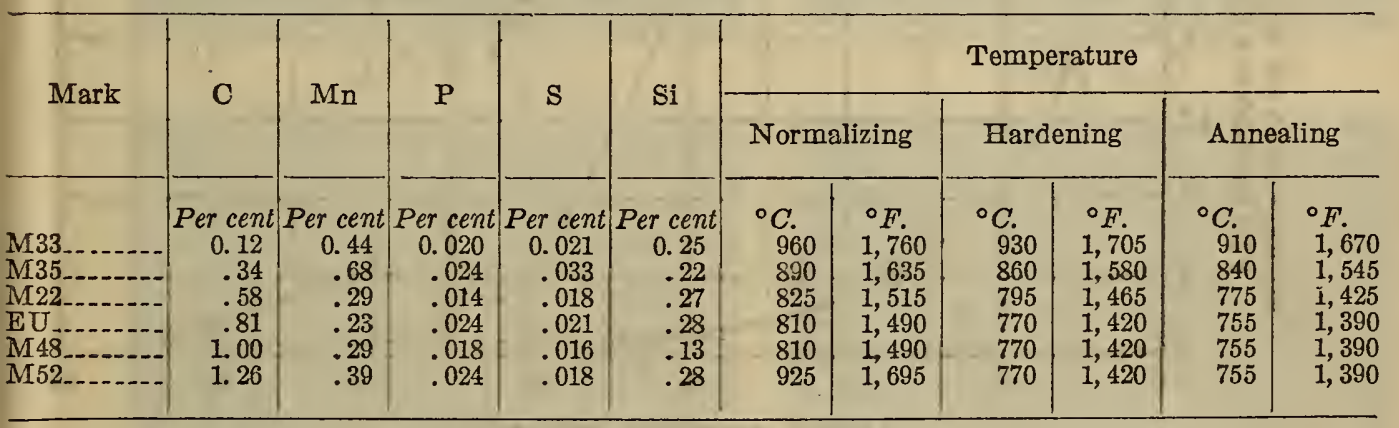

Time of holding at normalizing and tempering temperatures, 1 hour.

Time of holding at annealing and hardening temperatures, one-half hour.

All hardening by water quenching, followed immediately by tempering at $260^{\circ} \mathrm{C}$. $\left(500^{\circ} \mathrm{F}\right.$.).

\section{EFFECT OF CARBON CONTENT ON THE RESISTANCE TO WEAR}

The results of the tests on the annealed, normalized, and hardened steels, together with the Rockwell hardnesses, are summarized in Figure 5.

The carbon content apparently had little effect upon the wear of annealed steels. Rather surprisingly, the wear of the low-carbon normalized steels was greater than that of the annealed steels of 
similar carbon content, but with increasing carbon content the wear rate of the normalized steels decreased rapidly, approaching, in the high-carbon range, the relatively high wear resistance of the hardened steels. The wear of the hardened steels decreased rapidly and regularly with increasing carbon content in the lower ranges of carbon. In the higher ranges, however, increased carbon did not materially affect the wear resistance.

The microstructures of the annealed steels are shown in Figure 6, of the normalized steels in Figure 7, and of the hardened steels in Figure 8.

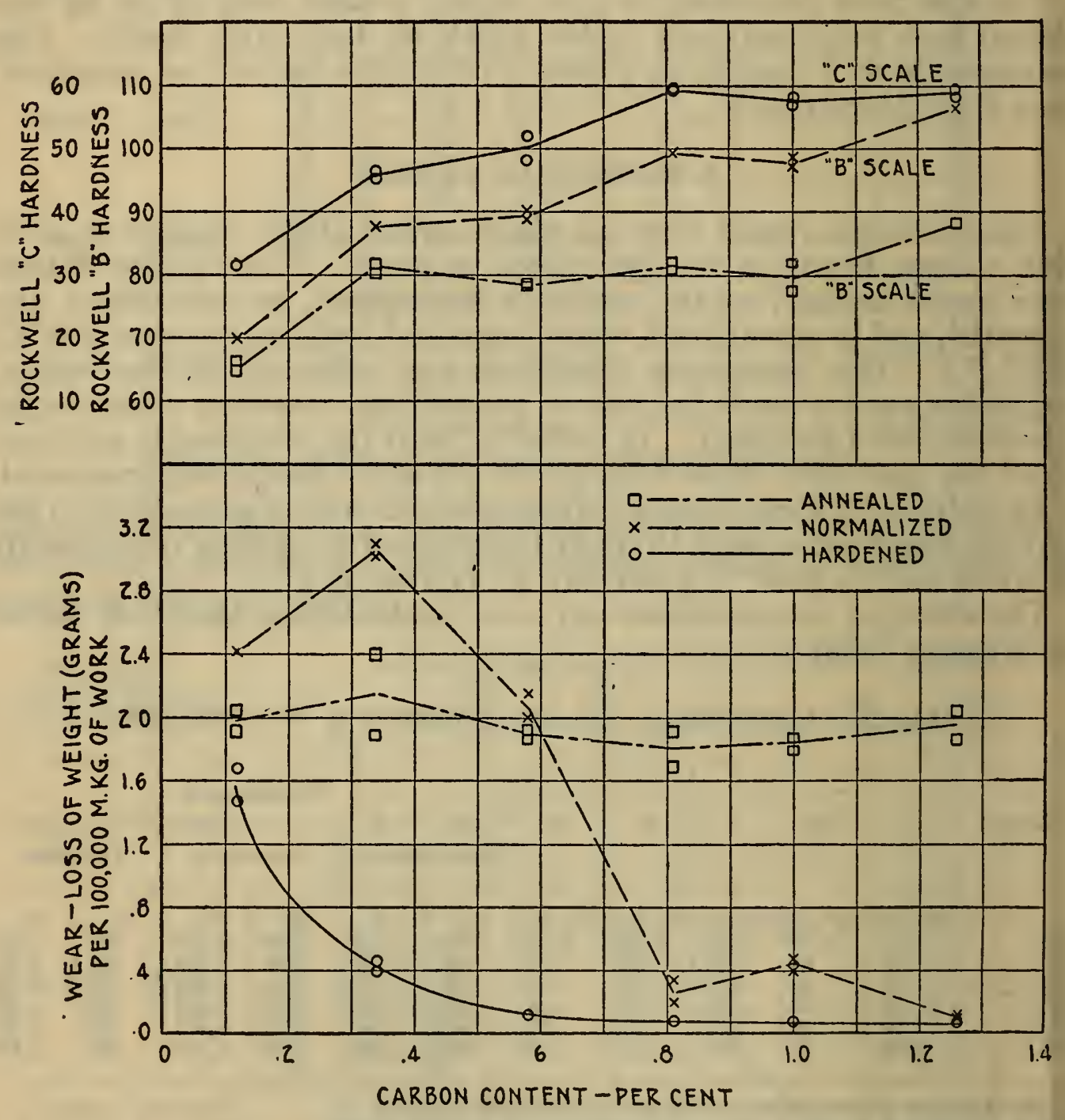

Figure 5.-Effect of carbon content on the wear of cabon steels tested in the Amsler machine

\section{EFFECT OF TEMPERING TEMPERATURE ON THE RESISTANCE TO WEAR}

The effect of tempering temperature on the resistance to wear of the 0.81 per cent carbon steel was studied. An attempt was made to test this steel as hardened and also as tempered at $150^{\circ} \mathrm{C}$. $\left(300^{\circ} \mathrm{F}\right.$.), but trouble was experienced due to cracking of the specimen. The results of the tests, together with the hardness determinations, are summarized graphically in Figure 9. These curves show that in- 
B. S. Journal of Research, RP348

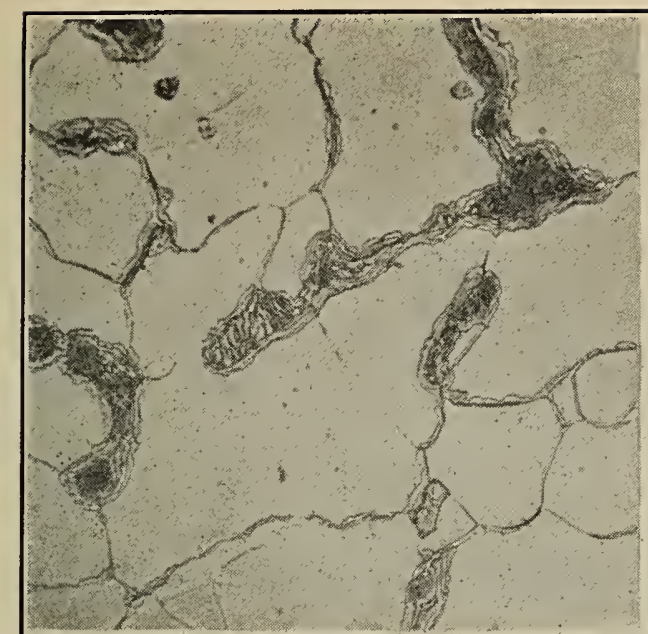

\section{$0.12 \% \mathrm{C}$}

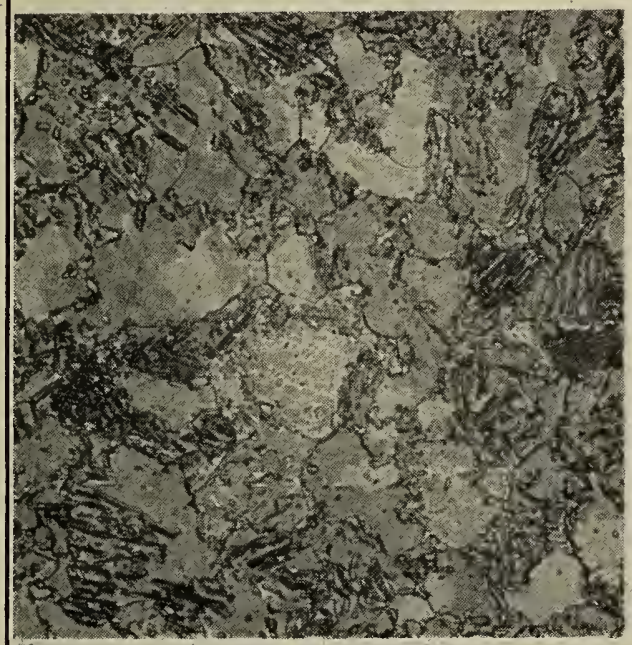

\section{$0.58 \% C$}

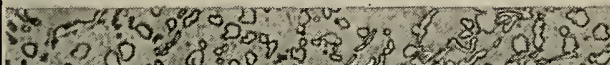

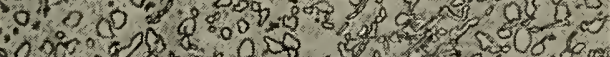

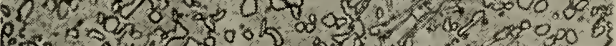

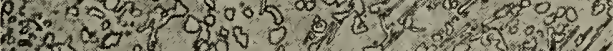

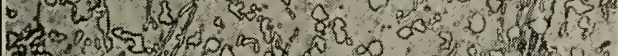

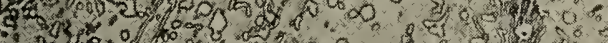
: 2. 10.

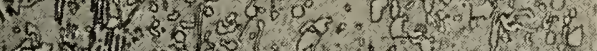

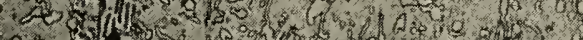
$0 \%$.

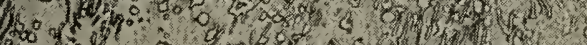

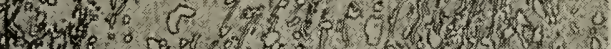

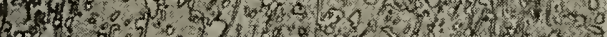

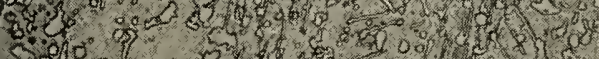
t.5. 00 of

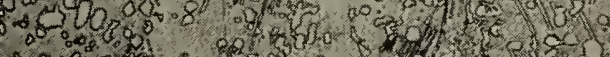

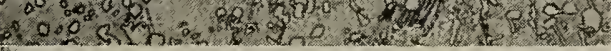
$1.00 \% C$

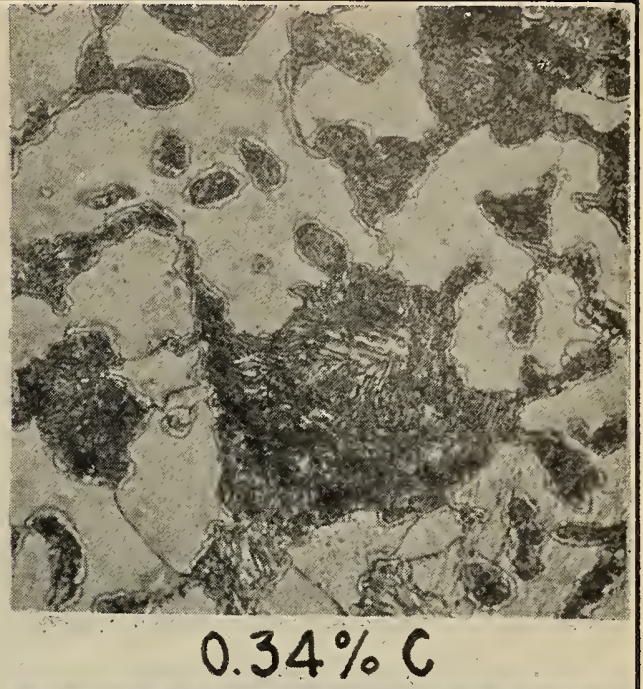

7.6.

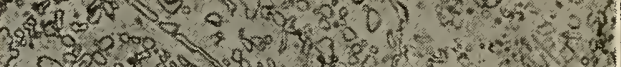

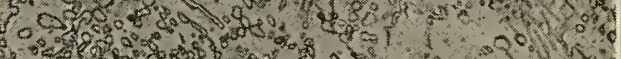

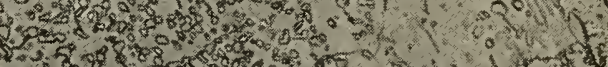

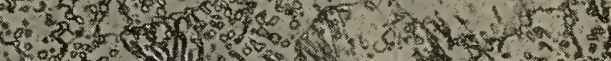
$-0 \%$. N I \% o.

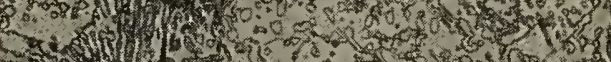

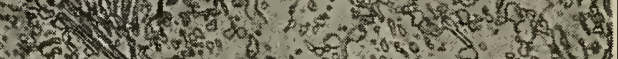

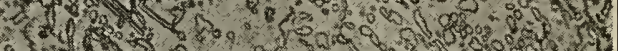

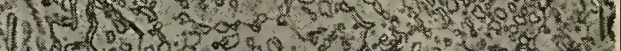

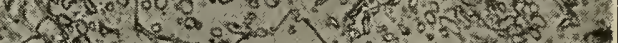
1.8

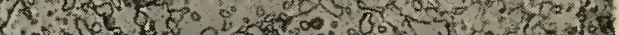

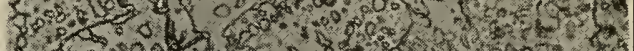
Ris. $0.81 \% C$

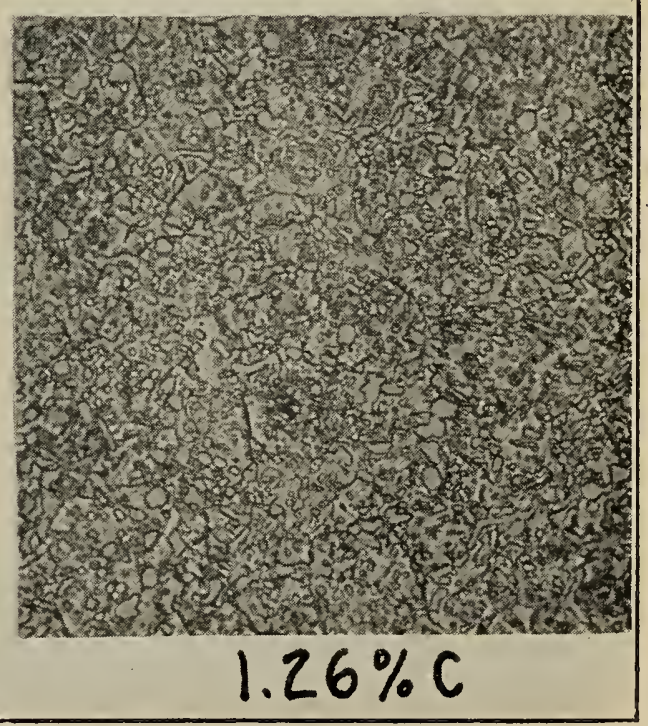

FIGURE 6.-Microstructures of the annealed steels. $\times 500$ Etched with 2 per cent nitric acid in alcohol. 
B. S. Journal of Research, RP348

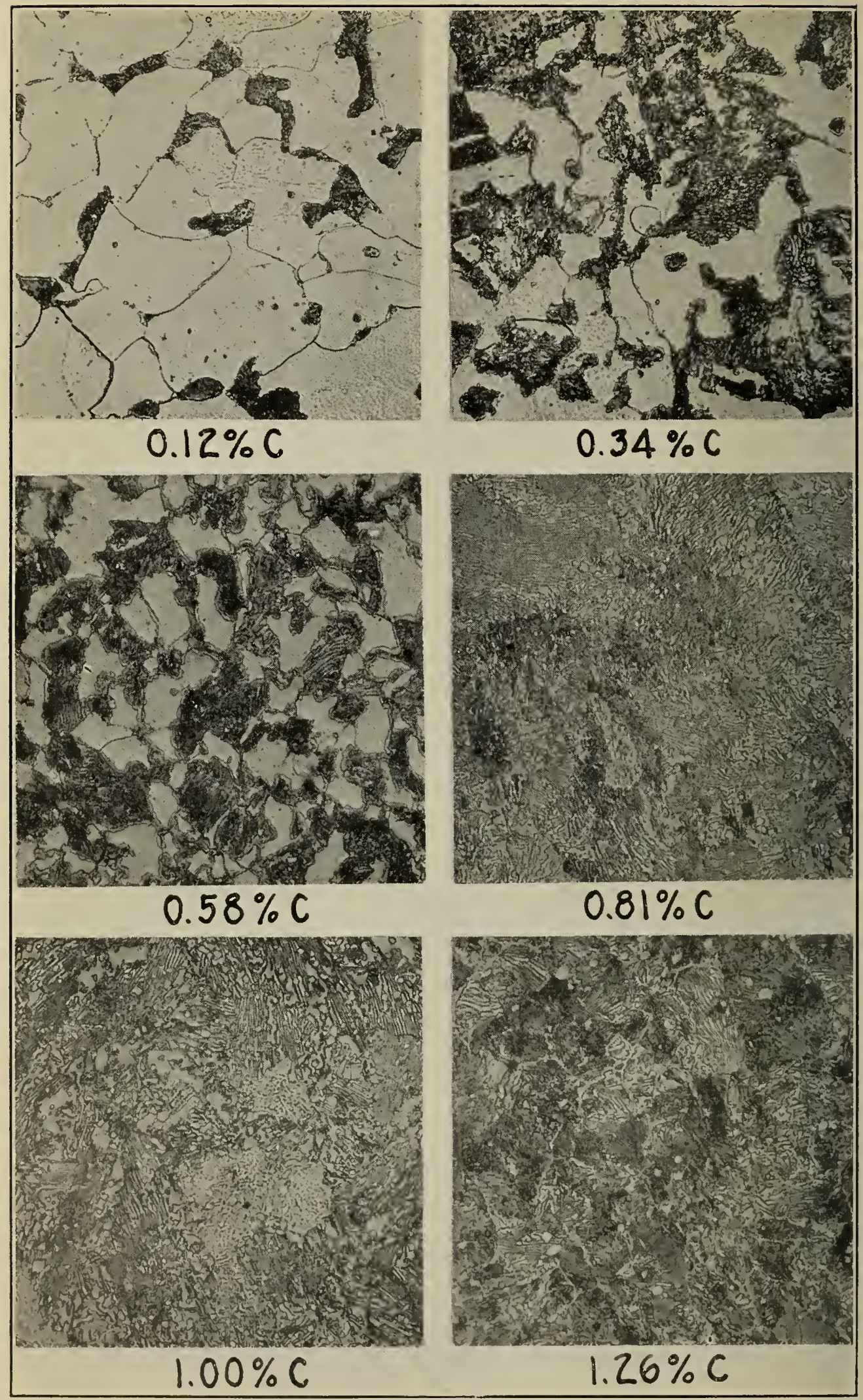

FIGURE 7.-Microstructures of the normalized steels. $\times 500$ Etched with 2 per cent nitric acid in alcohol. 
B. S. Journal of Research, RP348
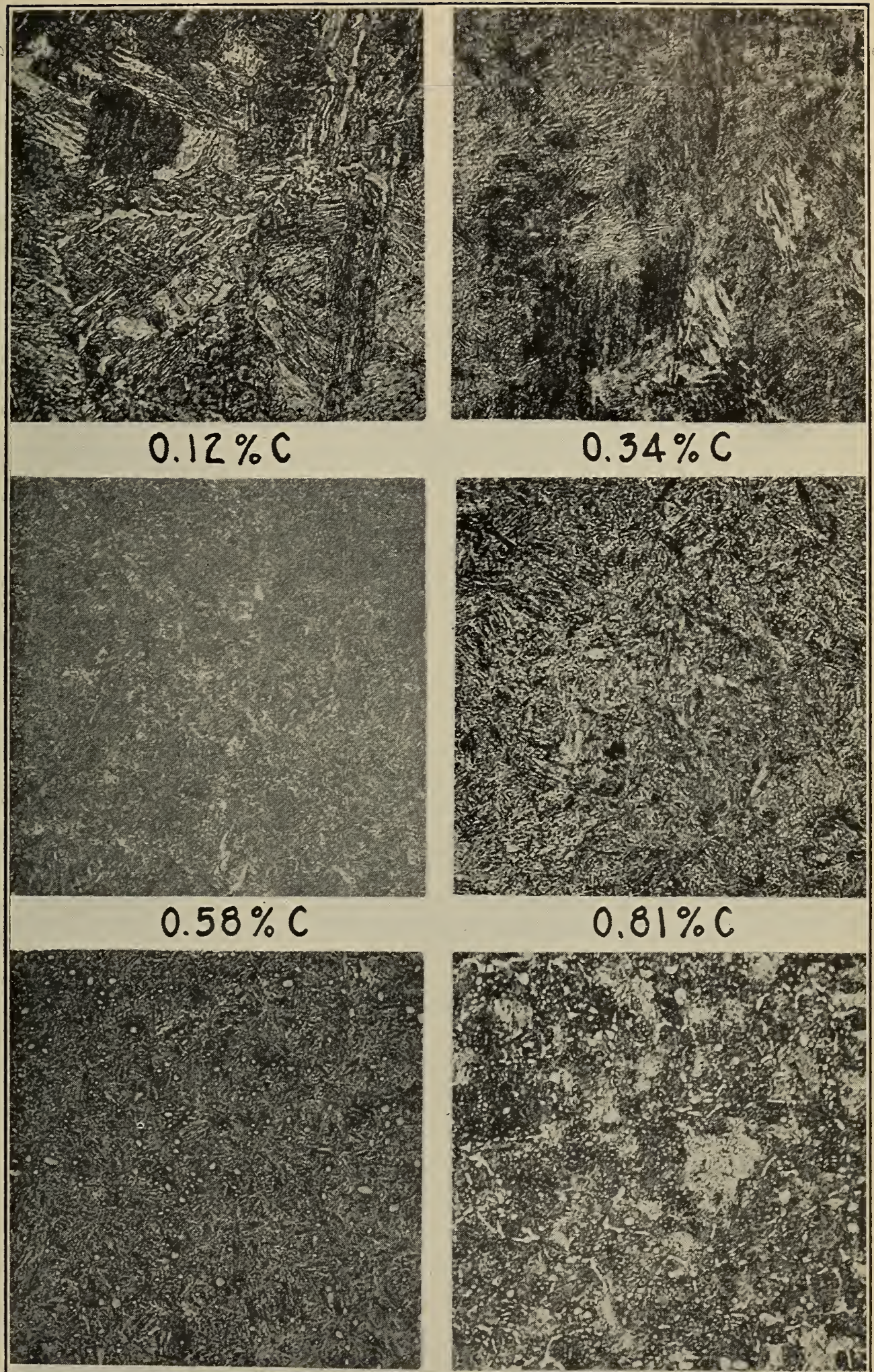

$1.00 \% \mathrm{C}$

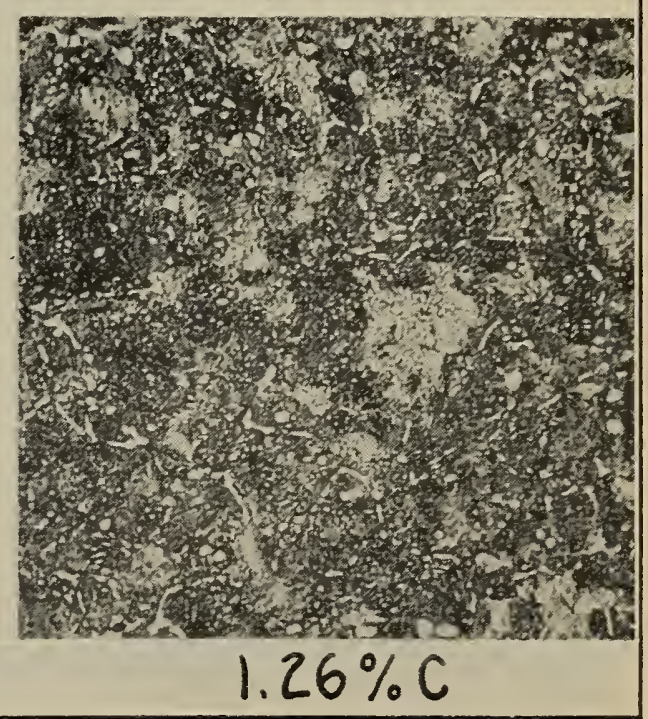

FigURE 8.-Microstructures of the hardened stee?s. $\times 500$ Etched with 2 per cent nitric acid in alcohol. 


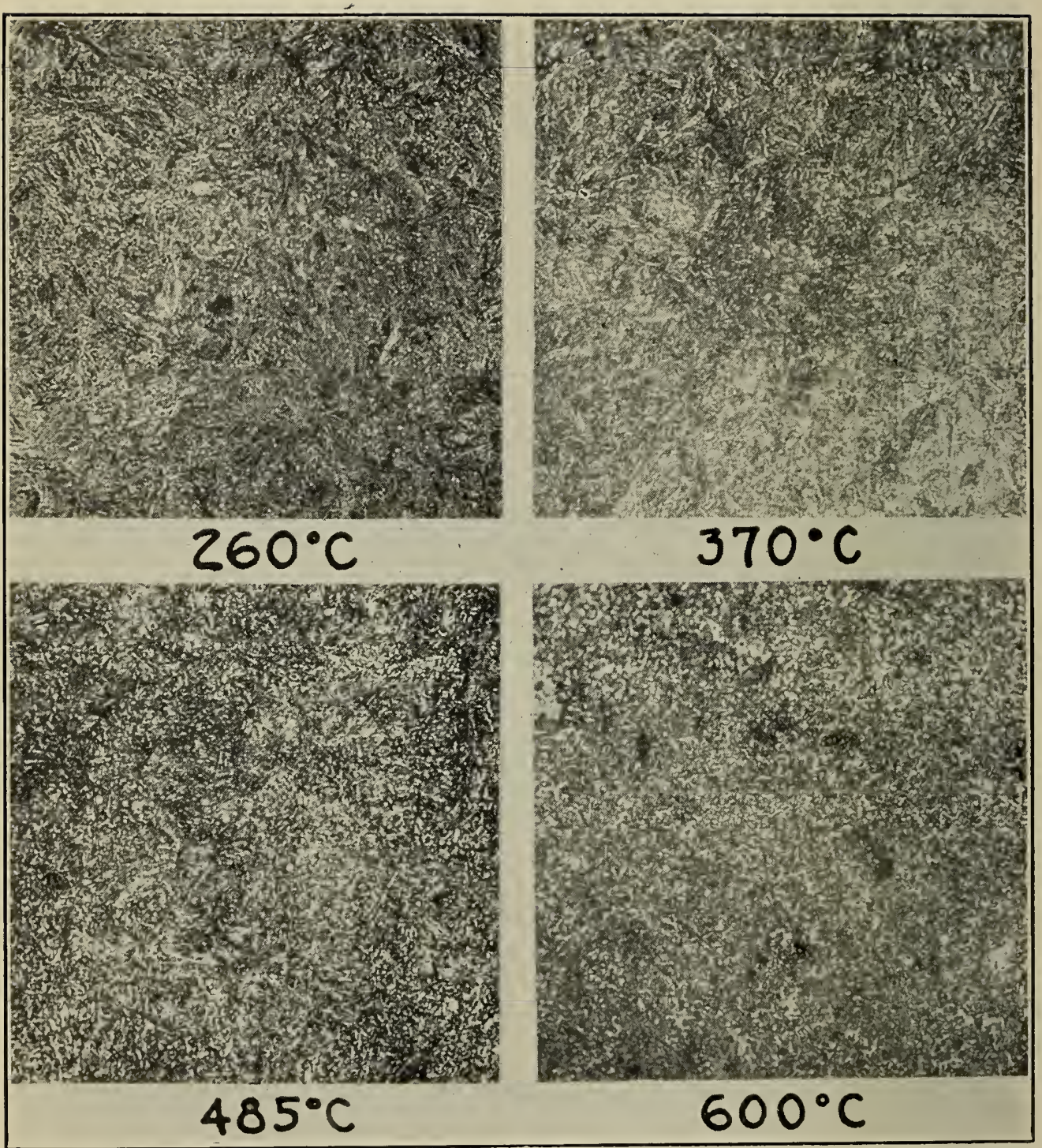

Figure 10.-Microstructures of the tempered 0.81 per cent carbon steel. $\times 500$ Etched with 2 per cent nitric acid in alcohol. Tempered at temperatures indicated. 
crease in tempering temperature progressively lowered the resistance to wear of eutectoid carbon steel as determined in the Amsler machine.

The microstructures of these steels are shown in Figure 10.

\section{EXAMINATION OF THE ABRADED SURFACES}

A study was made of the structures of the steels adjacent to the worn surfaces. The appearance of these structures in the steels representing the lowest and highest carbon contents are shown in Figure 11.

The low-carbon steel showed marked distortion of the grains near the surface after wear in all conditions of heat treatment. The gradation from distorted to normal structure can be seen in the micrographs. The micrographs of the high-carbon steel do not show any such gradation on the picture, but by comparing the structure near

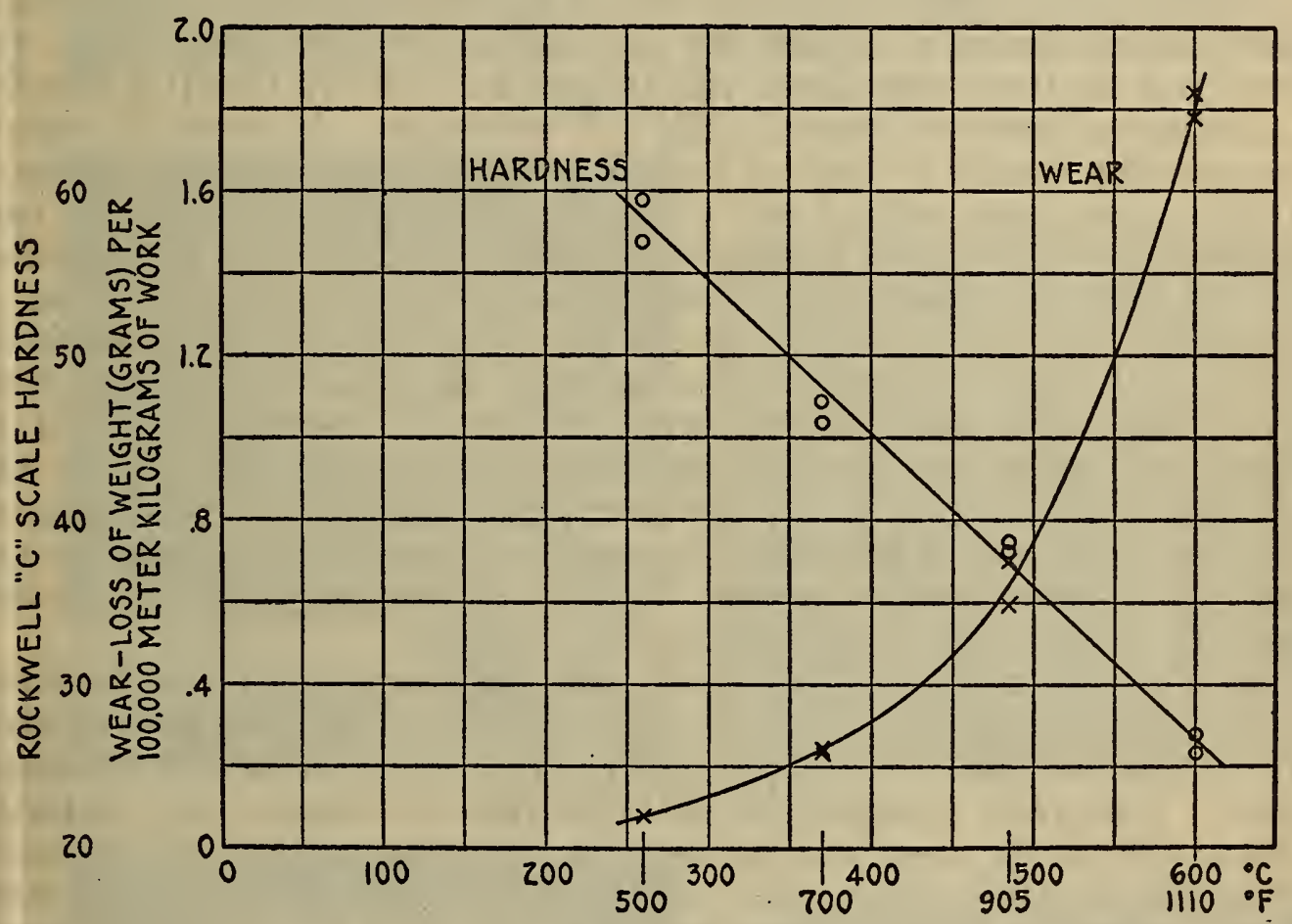

TEMPERING TEMPERATURE

FIGURE 9.-Effect of tempering temperature on the wear of an 0.81 per cent carbon steel

the surface with the corresponding normal structure shown in Figures 6,7 , and 8 it can be seen that the entire layer of metal adjacent to the surface shown in the micrographs of the normalized and hardened steels was so severely distorted as to obliterate the base structure entirely. The structure of these two steels slightly below the worn surface could not be resolved under the microscope even when viewed at a magnification of 2,000 diameters. The structure of the annealed high-carbon steel slightly below the worn surface showed evidences of the carbide particles having been brought closer together, presumably by the distortion of the surface layers. Prolonged etching failed to reveal the ferrite boundaries adjacent to the surface. These boundaries were easily revealed at some distance below the surface. 
Microscopic examination of the normalized 1.00 per cent carbon steel revealed some interesting and unusual features in the structure adjacent to the surface. At one point it was found that a distorted structure extended inward for some distance and, instead of merging gradually into the normal structure, was sharply separated from it by a wavy boundary. The appearance of this structure is shown in Figure $12(a)$.

At other points adjacent to the surface, the same specimen showed no definite evidences of distortion of the structure at 500 magnifications. At 2,000 magnifications, however, a thin layer of severely distorted structure was found, as shown in Figure $12(b)$. The normal structure at 2,000 magnifications is shown in Figure $12(c)$.

\section{DISCUSSION OF RESULTS}

Despite the fact that the Amsler wear testing machine has many peculiarities, most of which are at best imperfectly understood, the results of the tests embodied in this report have shown that it is possible to secure consistent results with this machine. In order to secure comparable results on two or more materials it is necessary to standardize upon some sort of test conditions, and then, if sufficient care is taken in the conduct of the tests, reliable data should be obtained.

The interpretation of test results in terms of the application of materials for service should be attended by considerable discrimination. Attempts to predict the behavior of metals in service from wear-resistance data secured with the Amsler machine should be made only when the service conditions involve combined rolling and sliding fraction under relatively heavy pressures of a type similar to that encountered in the Amsler machine. Results obtained by one method of investigation of wear usually can not be applied to service conditions involving wear of a different kind.

It is a fact that in the minds of many engineers the terms hardness and wear resistance are synonymous, and this opinion is evidenced every time the specification for a part to resist wear calls for a hardened steel. Generally speaking, it is true that the harder the material, the better is its wear resistance. In the case of the carbon steels reported in this paper, the high-carbon steels showed a greater wear resistance than the low-carbon steels and the hardened steels showed a higher wear resistance than the normalized steels, which, in turn, with the exception of the low-carbon range, showed a higher wear resistance than the annealed steels.

From a study of the data and the microstructures of the steels tested, it is evident that a martensitic, or rather a martensitic,troostitic structure is the most favorable for resisting wear of the type studied. Although both the annealed and the normalized steels in the high-carbon ranges are relatively soft as compared with the hardened steels, their resistance to wear varies widely. The normalized high-carbon steels show a resistance to wear almost as great as that of the hardened high-carbon steels, while the annealed highcarbon steels show a relatively poor resistance to wear. The structures of these normalized and annealed high-carbon steels vary markedly. They may be divided into two classes. The structures of the normalized steels are of lamellar pearlite, whereas those of the an- 


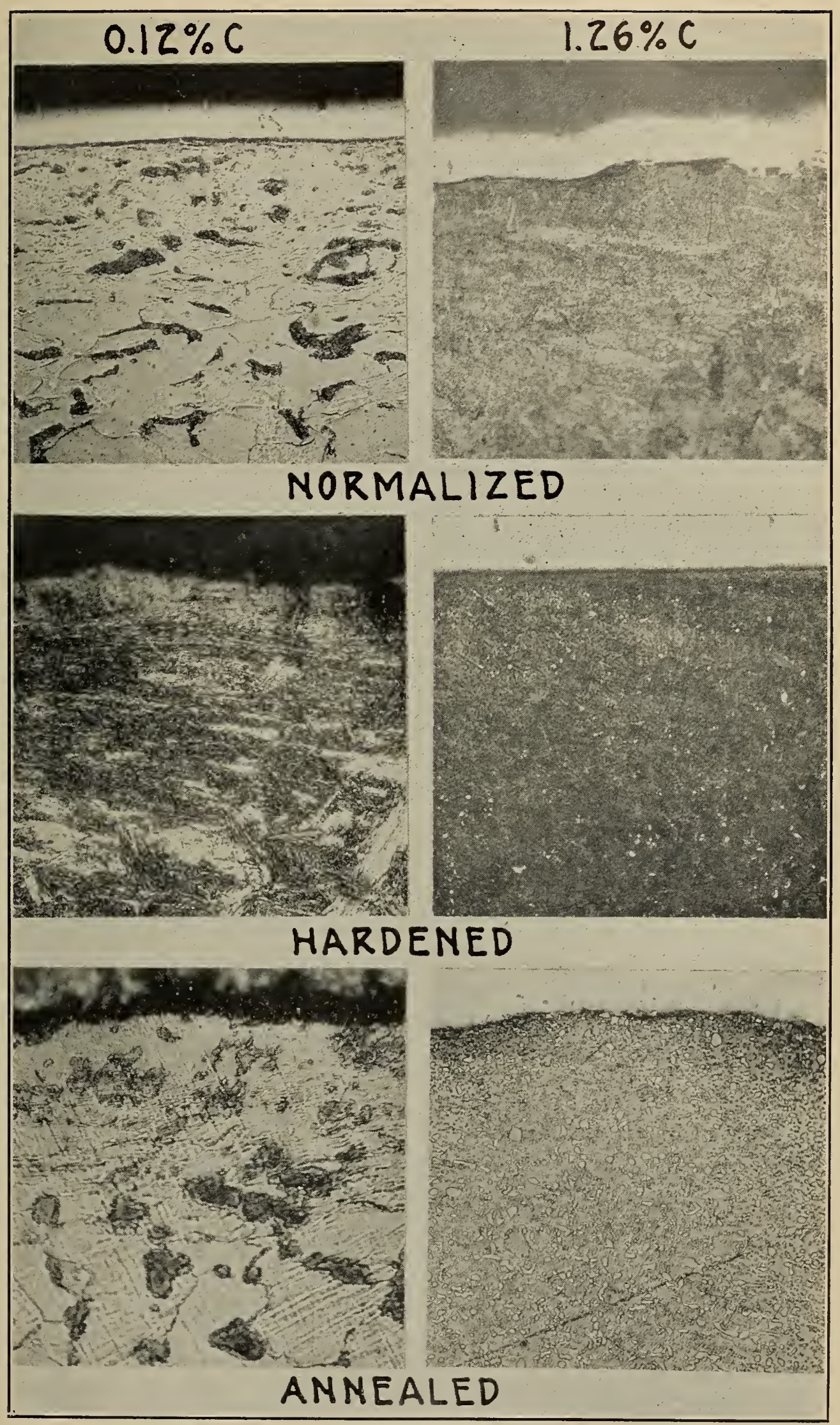

FIGURE 11.-Micrographs of the structures adjacent to the worn surface of the low and high carbon stee?s tested. $\times 500$ Etched with 2 per cent nitric acid in alcohol. 


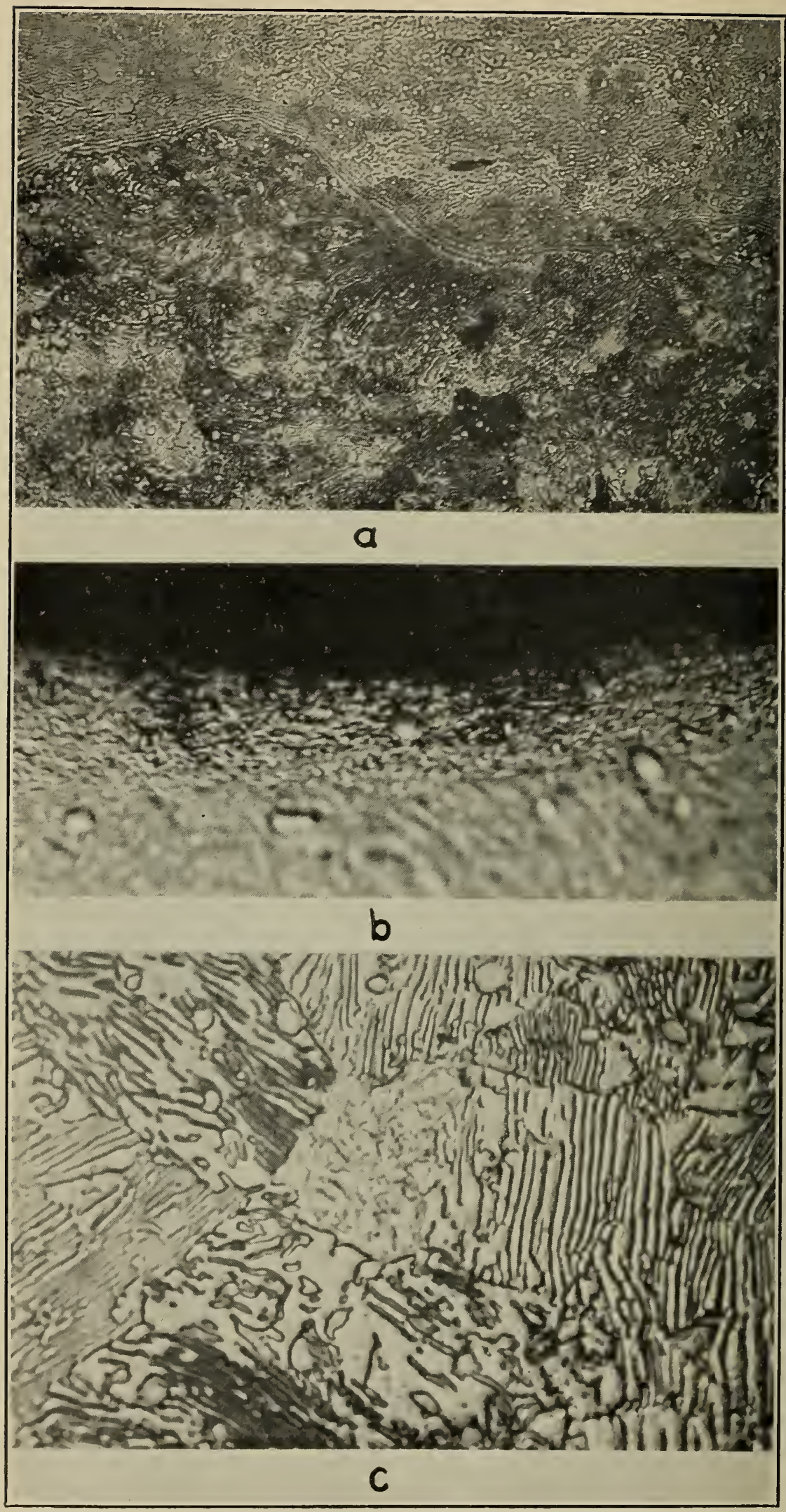

Figure 12.-Some unusual features in the structure adjacent to the wearing edge of a normalized 1.00 per cent carbon steel

Etched with 2 per cent nitric acid in alcohol. a, Micrograph showing a sharp line of demarcation between distorted and normal structure. $\times 500 ; b$, micrograph showing a thin layer of severely distorted structure at the wearing surface. $\quad \times 2,000$; $c$, normal structure, $\times 2,000$. 
nealed steels are mostly spheroidized cementite and ferrite. This spheroidization was the result of the relatively slow cooling through the critical range undergone by the steels during the annealing treatment. From the curves shown in Figure 5, it would seem that lamellar pearlite is quite resistant to wear. This is in accordance with results reported by Lehman. ${ }^{5}$ In making wear tests on cast iron he found that the main factor which governed the resistance to wear of cast iron was the percentage of pearlite.

Evidently the presence of either free ferrite or free cementite (as spheroids) is detrimental to the wear resistance of normalized carbon steels. That free ferrite is distinctly harmful is shown by the wear of the low-carbon steels, all of which exhibited low resistance to wear. The microstructures of these steels (fig. 7) show the normal amount of free ferrite.

In the high-carbon range, the 1.00 per cent carbon steel, as normalized, showed a somewhat greater loss of weight than either the 0.81 per cent or the 1.26 per cent carbon steel. (Fig. 5.) From the microstructures of these steels (fig. 7) it will be observed that the 1.00 per cent carbon steel shows relatively numerous patches of free cementite. The 1.26 per cent carbon steel, although containing, of course, more excess cementite than the 1.00 per cent carbon steel, has most of its excess cementite in the form of thin envelopes surrounding the pearlitic grains.

As previously mentioned, the normalized low-carbon steels showed slightly less resistance to wear than the same steels when annealed. An examination of the micrographs of these steels (figs. 6 and 7 ) revealed that the pearlite in the annealed steels was surrounded by cementitic envelopes. The normalized steels did not show this feature in their structures. These envelopes, being rather continuous and much stronger than the surrounding ferrite, are undoubtedly responsible for the wear resistance of the low-carbon annealed steels being greater than that of the same steels when normalized.

As would be expected, tempering a hardened steel resulted in a gradual lowering of its resistance to wear. It is interesting to note that the hardened 0.81 per cent carbon steel tempered at $600^{\circ} \mathrm{C}$. $\left(1,100^{\circ} \mathrm{F}\right.$.) showed practically the same resistance to wear as the same steel annealed. The microstructures of these two steels (figs. 6 and 10) seem, upon first glance, to be quite different, but a closer examination reveals that the tempered steel shows distinct evidence of spheroidization.

The microstructures of the steels adjacent to the worn surfaces show that the type of wear studied in this report was generally accompanied by severe distortion of the structure. This suggests a reason for the detrimental effect of spheroidal cementite. It would appear that cementite occurring as spheroids is easier to dislodge under severe rubbing action than cementite which occurs in lamellar pearlite or as relatively thin, continuous envelopes surrounding pearlitic grains in hypereutectoid steels.

5 H. Lehman, Wear Tests on Cast Iron, Foundry Trade JJ., p. 36, January 13, 1927; p. 35, February 24, 1927. 


\section{SUMMARY AND CONCLUSIONS}

The resistance to wear of a group of carbon steels was studied by means of the Amsler wear-testing machine in which the material is subjected to combined rolling and sliding friction under heavy pressures. Annealed carbon steels gave relatively poor wear-resisting qualities for all carbon contents. Normalized steels showed low wear resistance in the low-carbon range, but had greatly improved wear resistance in the high-carbon range. The hardened steels showed low wear-resistance in the lowest carbon ranges, but as the carbon content increased the wear resistance increased very rapidly until about 0.6 per cent carbon. Above this percentage the wear resistance increased very slowly. Tempering a hardened steel resulted in a gradual lowering of its wear resistance.

A martensitic-troostitic structure was the most favorable for resisting wear of the type studied. Properly normalized high-carbon steels, which showed a structure of lamellar pearlite, had almost as good wear resistance as the hardened steels. Annealed high-carbon steels, showing a structure predominately spheroidized cementite, had relatively poor resistance to wear. Apparently free ferrite or free cementite (as spheroids) are detrimental to the resistance to wear.

Wear of the type studied usually resulted in marked distortion of the structure of the steel adjacent to the worn surface.

\section{ACKNOWLEDGMENTS}

The author desires to express his grateful appreciation to Houston $\mathrm{Babb}$, junior scientific aid, for his conscientious assistance in many of the tests.

Washington, April 29, 1931. 